\title{
The environmental, social and ethical aspects of multinational corporations exploiting oil resources in Ecuador
}

\author{
A. Newcombe, A. Evangelio, P. Revilla, T. Laranjeiro \\ \& S. F. Hansen \\ DTU Environment, Technical University of Denmark, Denmark
}

\begin{abstract}
Extraction of oil promises economic growth in many developing countries but almost inevitably brings environmental and social degradation with it. In this paper we explore the environmental, social and ethical aspects of multinational companies' (MNCs) oil exploration and production in Ecuador and we analyze several different protective regulatory management strategies that could help eliminate negative impacts. We use Drivers Pressures State Impacts Responses (DPSIR)-analysis to understand the interconnectivity of the current situation whereas we use stakeholder analysis to identify the most appropriate regulatory response. We find that there is scientific consensus that pollution from oil production by MNCs has caused an environmental disaster, a widespread health emergency and serious detrimental social impacts. This raises fundamental questions about whether it is ethically justifiable that MNCs disregard legal rules from their country of origin to profit from limited and ineffective environmental law in developing countries. A number of regulatory strategies exist that could resolve the situation including; the temporary banning of MNCs to extract oil, expansion of the Yasuní-ITT initiative, which allows the Ecuadorian government to receive funds from the international community for refraining from oil exploitation, compensation and remediation and the development of environmental law and policy. Selecting the most appropriate strategies requires stakeholder involvement and consideration of their interests. Through our stakeholder analysis we identified a wide range of stakeholders ranging from the indigenous people to MNCs such as Chevron. The interests, influence and political and economical power of the identified stakeholders differ substantially and unfortunately it was found that the most impacted stakeholders were quite
\end{abstract}


often the least influential. We recommend that a heavy focus is put on the use and implementation of the 'precautionary' principle and the 'polluter pays' principle and that public participation is encouraged to provide a legal framework to support sustainable development in Ecuador.

Keywords: oil extraction, developing countries, DPSIR, stakeholder analysis, precautionary principle, public participation.

\section{Introduction}

Profit from the extraction of oil is a large part of the economy in Ecuador, representing almost half of the country's gross national product (GNP). However, oil extraction in the northeast Ecuador has been controversial due to the environmental, social and health impacts associated with exploration and production of oil. In over 20 years of operation in the area, MNCs (among others the American company Texaco now owned by Chevron) extracted more than 2 billion barrels of crude oil from Ecuador making a net profit of \$490 M US. Over the course of this time, over 18 million gallons of produced waste were spilled into the environment without treatment or monitoring, despite oil industry standards recommending that wastes should be reinjected back into the ground (San Sebastian et al. [1]). Texaco followed these standards in the USA, including establishing pits for temporary storage of waste lined with industrial tarp to prevent seepage contaminating groundwater. In Ecuador however, the standards were ignored. This raises fundamental questions about whether it is ethically justifiable that MNCs disregard legal rules from their country of origin to profit from limited and ineffective environmental regulation and laws in developing countries. In this paper, we explore environmental, social and ethical aspects of MNCs oil exploration and production in Ecuador and we analyse several different protective regulatory management strategies that could help eliminate negative impacts. In the following we first introduce the environmental, health and social impacts that oil extraction has had in Ecuador. We then present our use of Drivers Pressures State Impacts Responses (DPSIR)-analysis to understand the interconnectivity of the current situation and finally we use stakeholder analysis to identify the most appropriate regulatory response.

\section{Oil multinational corporations' impacts in Ecuador}

\subsection{The impacts on the local environment}

All stages of previous oil extraction operations in Ecuador (including exploratory drilling, commercial extraction, and transport through pipelines) have caused devastating environmental damage on what used to be a uniquely diverse ecosystem. Direct environmental impacts from oil operations in the Ecuadorian Amazon include deforestation from trail clearing, access roads, drilling platforms and pipelines, and contamination from oil spills and pollution discharge (Finer et al. [3]). For instance the MNC Texaco spilled more than 18 billion gallons of oil in the area during twenty years of operation in the region (Mecham [2]). A report 
published by the Centre for Economic and Social Rights in the United States shows that, as a result of this misconduct, the levels of toxic polynucelear aromatic hydrocarbons found in drinking, bathing and fishing waters were 10 to 10000 times higher than those accepted by the U.S. Environmental Protection Agency Guidelines. Independent water analyses found that the total petroleum hydrocarbons in some freshwater streams in Ecuador reached levels of 144-288 times the limit permitted by European Union legislation. It has been reported that many rivers once rich in fish now support little or no aquatic life, and that cattle have been dying from drinking them (San Sebastian et al. [1]; San Sebastian and Hurtig [4, 9, 10]).

Further to this intense pollution, in the last few decades Ecuador has suffered one of the highest rates of deforestation in the world, and the highest in South America (UN [5]). The Amazon is not only a biodiversity hotspot, but also a natural sink for ozone and is invaluable in terms of stable global climatic conditions because of $\mathrm{CO}_{2}$ sorage (Shukla et al. [6]). A study by Viña et al. [7] using satellite imaging concluded that the deforestation in the area is most likely associated with oil exploration due to the associated road construction. According to Mecham [2], 30\% of the Ecuadorian Amazon has been deforested and/or polluted either directly by the oil industry or indirectly by colonisation accelerated by oil related road construction. According to a business magazine, the Business Pundit [8] it is one of the 10 worst environmental disasters caused by companies. The pollution caused by MNCs in the area has also been linked to some serious health and social impacts.

\subsection{Oil production and human health}

Drilling oil in Ecuador has caused and is causing a myriad of health problems to local indigenous groups. Independent health risk studies have demonstrated that the number of spontaneous abortions, cancers, childhood leukemia and other harmful effects in humans have all significantly increased as a result of pollution and oil spills in water and fields (San Sebastian et al. [1]; San Sebastian and Hurtig $[4,9])$. The Amazon has approximately 20\% of the world's freshwater resources (National Geographic [11]), but independent research has revealed that freshwater rivers in the area exceed permitted levels in the area for total petroleum hydrocarbon content and toxic polynuclear aromatic hydrocarbons (San Sebastian and Hurtig [9]). Over half of the wells and oil stations in Ecuador are in areas where families are living within $500 \mathrm{~m}$. Around $40 \%$ of these families live within $50 \mathrm{~m}$ of the oil extractions. These families are losing farm animals and access to safe water and are suffering diseases due to the impact on the environment of oil extraction (Maldonado and Narvaez [12]). The most dramatic case is the Basura River, with almost 300 times the European Union permitted limit of 0.01ppm total petroleum hydrocarbons (San Sebastian and Hurtig [9]). The freshwater is used for bathing, drinking and fishing and it has been found that pregnancies in exposed communities were approximately 2.5 times more likely to end in spontaneous abortion than those in comparison communities (San Sebastian et al. [1]). The risk of childhood leukaemia was significantly elevated in exposed areas, compared to neighbouring areas without 
oil production (San Sebastian and Hurtig [10]). The three main pathways that oil or its components can affect humans are skin absorption, ingestion of contaminated products and inhalation. Skin absorption is especially dangerous for people who work directly with oil and those using resources which are exposed to oil, such as livestock, water or crops. Ingestion of contaminated products, in particular by people that live in proximity to oil plants, has been linked to a large number of cases of lung and rectal cancer. Skin absorption and ingestion of contaminated products are especially significant for the indigenous population who use rivers such as the polluted Basura River for bathing and drinking water. Inhalation can affect populations living a larger distance from the oil fields, causing symptoms like eyes and skin irritation. The communities in close proximity to oil extractions are exposed to oil through all three pathways. The denser oil components can arrive more easily to groundwater resources than lighter components or can be ingested by animals that humans subsequently eat. Lighter components can evaporate and arrive to distant areas by air flow, becoming a problem for a larger population within Ecuador (Manuel Amunárriz Institute of Epidemiology and Community Health [13]). It has been found that "women living in communities close to the oil fields have reported higher rates of adverse physical symptoms such as skin mycosis, sore throat, headache, red eyes, ear pain, diarrhea and gastritis" (San Sebastian and Hurtig [10]). Independent researchers have labelled the situation as a national medical emergency (San Sebastian and Hurtig [14]).

\subsection{Social changes due to oil extraction}

A lot was initially expected from the oil exploration in Ecuador when it comes to the positive evolution that it might have on the country's economy. In the beginning of the oil boom a rapid increase was observed in per capita income and GNP, but since then the national debt has risen from \$200 million in 1970 to more than \$12 billion in 1994 (World Bank, 1991 cited in CESR [15]). Roughly $75 \%$ of the money from crude oil taken from Ecuador goes to the oil companies. About $18 \%$ goes to paying off a huge foreign debt and most of the remainder goes to covering military and other government expenses. Less than $3 \%$ is spent on health, education, and other programs designed for helping the public (Tolan [16]). According to the World Bank (1991 cited in CESR, [15]), this skewed distribution of oil money has resulted in great and profound social changes. The poverty rate rose from less than 50 to 65 percent from 1975 to 1992 and the urban poor, colonists and indigenous groups have almost uniformly suffered worsening conditions (Menacho 1993 cited in CESR [15]). Only a very small part of the population benefited from oil exploration and the majority of these benefits have gone to the elite and the military. Besides the social changes that come with the unequal distribution of wealth, there is a multitude of social changes that relate to road construction. The roads built during Texaco's oil exploration were used by farmers to colonize deep into the Ecuadorian Amazon, drastically changing the ways of life of the natives (Valdivia [17]). By 1992, only around $8 \%$ of the Oriente region belonged to the indigenous communities, as opposed to exclusive use over 30 years ago (Haller et al. [18]). This was in 
part an attempt "to 'civilize' native peoples and integrate them into the dominant national culture" (Kimerling [19]). The result of this "movement" was that these natives found themselves at the bottom of society, treated as a cheap labor force. Their beliefs were rejected, their traditions and culture torn apart. There are about 8 indigenous nations in the Oriente region, totaling between 100,000 and 250,000 people, each with different cultures and traditions. Some are being driven to extinction (CESR [15]). The oil driven national development is, from the natives' point of view, an ethnocide.

\subsection{An ethical view of oil exploration in Ecuador}

According to the Ecuadorian NGO Amazon Defense Coalition [20], the United States industry standards were ignored repeatedly, and misconduct in this operational period included the practice of not lining oil pits with industrial tarp, abandoning unlined pits filled with oil sludge, draining of approximately 16 million gallons of polluted 'produced' water directly into rivers and streams, and the burning of natural gas, also known as 'flaring'. Ecuadorian policymakers had extremely limited experience in environmental management of oil production and relied on the MNC Texaco to responsibly protect the environment during oil extraction. General Rene Vargas Pazzos, a key policymaker during the oil rush, has stated that "Texaco was the operator. We did not interfere with technical decisions because that was Texaco's responsibility”. There have been some attempts to ensure that MNCs are not exploiting developing countries, but the absence of effective monitoring to control the relationships between MNCs and host countries permits MNCs to operate with virtual impunity. These MNCs are taking advantage of the much weaker environmental laws in these countries to maximize the profits derived from extracting their resources (Cueto [21]). This is an important ethical issue to deconstruct - if the law in your home country is too strict to make the kind of profits you desire, is it ethical to conduct business in a country without such relatively developed industry monitoring and environmental law?

\section{Analysis}

Having reviewed the environmental, health, social and ethical aspects of MNCs oil exploration and production in Ecuador, we find that there is scientific consensus that pollution from oil production by MNCs has caused an environmental disaster, a widespread health emergency and serious detrimental social impacts. In order to understand the interconnectivity of the current social aspects and identify main powers and interests, we first completed a Drivers Pressures State Impact Responses framework analysis. This was followed by a stakeholder analysis to identify the most appropriate regulatory response leading to recommended regulatory strategies to improve the situation in Ecuador.

\subsection{Drivers Pressures State Impact Responses framework analysis}

A DPSIR analysis is an effective tool for an Integrated Environmental Assessment. It is a simplified representation of causal relationships between 
drivers, pressures, states, impacts and responses. Drivers are defined as the needs and consist of individual needs like food and water, secondary needs like mobility and macroeconomic needs like production and consumption (Kristensen [27]). The result of meeting these needs are pressures on the environment, such as emissions and use of resources. The state or quality of the ecosystems and human health is changed by these pressures. The impact is the change to biological, chemical or physical state of the environment. The responses are actions that policy makers, society and others have taken or can take.

As a first step of the DPSIR analysis a list of drivers, pressures, states, impacts and responses were identified. After extensive research on oil extractions in Ecuador, the lists of each DPSIR aspect were compiled and causal links were identified. Identified "Drivers" include the profit-driven oil industry, Ecuadorian economic growth and international energy demand. Oil MNCs are supported by large enough revenues so that almost nowhere is off limits to oil exploitation, and the fact that there are untapped reserves of crude oil beneath the Ecuadorian Amazon makes it a key driver behind oil extraction activities in Ecuador. Likewise, the Ecuadorian national economy is a driver identified that lies behind oil extraction activities, as it arguably has the ability to create economic growth and employment despite the negative outcome of previous decades. All the identified drivers eventually lead to more oil being extracted in Ecuador, resulting in many "Pressures" including climate change, change in land use, effects on human health, and pollution. Climate change contributions are extreme in this issue. Not only does the consumption of petroleum emit carbon dioxide, forest area reduction results in less carbon dioxide being used in photosynthesis. Present is point source pollution from unlined pits, spillages and direct drainage of produced water. Diffuse source pollution includes general runoff of petroleum pollutants and atmospheric pollution. In addition to the health effects mentioned previously, the land that previously was home to indigenous people has now another use, the extraction of oil.

Identified pressures are linked to the "State", or quality of the environment and human health. Key parameters that can be used to describe the States include river water quality, social capital, deforestation levels, soil pollution and human health quality. The pressures of point and diffuse source pollution affect the quality of soil and water in the area, and as the water is used for drinking, the quality of human health. The change in land use has caused deforestation and a decrease in social capital, as local communities have lost their homeland. The "Impacts" on human health have been previously mentioned, and these are linked to the quality of polluted water. There has been a loss of fertility in soil, due to oil pollution and the indirect impacts of deforestation. The impact of deforestation is a loss of loss of rainforest, habitat and biodiversity. Deforestation and impacts on human health have also resulted in the extinction of indigenous cultures and many social conflicts in the area. These impacts have caused a range of "Responses" from a range of stakeholders. Social protest has been a general public response to health, social and environmental impacts. An innovative response has been launched in the sense of the Yasuní-ITT initiative - an agreement made by the WWF, Greenpeace, and the Ecuadorian government to 
receive funds in return for leaving untapped reserves of oil and gas under the Amazon untouched. This is an attempt mainly in response to impacts such as increased atmospheric pollution, and the loss of rainforest, indigenous cultures and biodiversity. This will cover $20 \%$ of all Ecuadorian oil reserves. Yasuní-ITT initiative should pay \$3.6M US to keep the oil underground. This value is the $50 \%$ of the price of the oil in the area. The achievement of the Yasuní ITT initiative will be that 407 millions of tons of CO2 will not be emitted to the atmosphere and Yasuní National Park will be conserved. (Yasuní-ITT [29]).

Environmental management policies and monitoring standards are related, as policies cannot be effective without sufficient monitoring. A study by NaughtonTreves et al. [30] shows that there is a large difference between the legal status and actual management of Protected Areas in Ecuador. MNCs are required to carry out project-specific Environmental Impact Studies (EIS) prior to oil and gas exploration projects. The MNCs contract the firms that carry out these studies, a system which lacks independence, transparency, and typically fails to analyse long-term, cumulative and synergistic impacts of a combination of multiple gas and oil projects in the area (Finer et al. [28]). So although the areas are protected from development by law, the results of insufficient environmental monitoring are that development takes place in protected areas, and without respect to environmental legislation, resulting in environmental degradation. The results of implementing effective policy and monitoring will be a general improvement on the state of environment, including water, air, soil pollution and deforestation. As the drinking water quality will be improved by effective management and monitoring, it is expected to cause a gradual improvement of health in the area. Although DPSIR-analysis has been criticised for being too simplistic and subjective in nature (Svarstad et al. [31]) the usefulness of DPSIRanalysis should not be disregarded as they help to build an idea of where the real problems lie and how to solve them. The DPSIR-analysis is able to address some of the stakeholder analysis weaknesses, while the DPSIR-analysis shows how the stakeholders engage in order to identify the most appropriate regulatory measure.

\subsection{Stakeholder analysis}

A stakeholder analysis considers which entities influence and/or is influenced by the considered subject. It also analyses the different stakeholders influence according to how much they are affected or how much power they have over decisions. These stakeholders are defined as people or organizations with an "interest" in the topic (WHO [22]). By analyzing who "holds the cards", the decision-makers can choose where to focus their attention in order to obtain the best results, and stakeholder analysis has often been used in the past to assist in implementing a plan or policy (Schmeer [23]). The first step in our stakeholder analysis was to identify the stakeholders involved by researching the issue. After the stakeholders were identified, we investigated how much influence over decisions a stakeholder has and how much interest a stakeholder has in the issue. Following this, relationships between stakeholders were identified.

As an outcome of our stakeholder analysis a Venn diagram was prepared in order to illustrate the relationship between different stakeholders identified in 
this case (see figure 1). The Venn diagram shows the influence of each stakeholder and the interactions between them. In the centre of the Venn diagram lies the case of oil extraction in the Ecuadorian Amazon and the closer a given stakeholder's circle is to the middle of the diagram the higher their interest in the issue. The bigger the stakeholder's circle is the higher influence the stakeholder has. For example the MNCs have been identified as the most influential stakeholder in this analysis because of their economic power. The more the circles of two or more stakeholders overlap, the more interaction the two or more stakeholders are believed to have. The most relevant stakeholders involved in the issue are MNCs, Government of Ecuador, the local people and indigenous living in an oil operation area. The strongest relationship has been identified to be between MNCs and the Ecuadorian Government, as the economy of Ecuador is reliant on oil exports (Index Mundi [24]). The government is letting MNCs drill in their country despite the environmental and health consequences. The relationship between the Ecuadorian Government and the society of the area has a small bond, since, on this issue the government places higher priority on economic framework rather than on improving the overall living conditions in Ecuador.

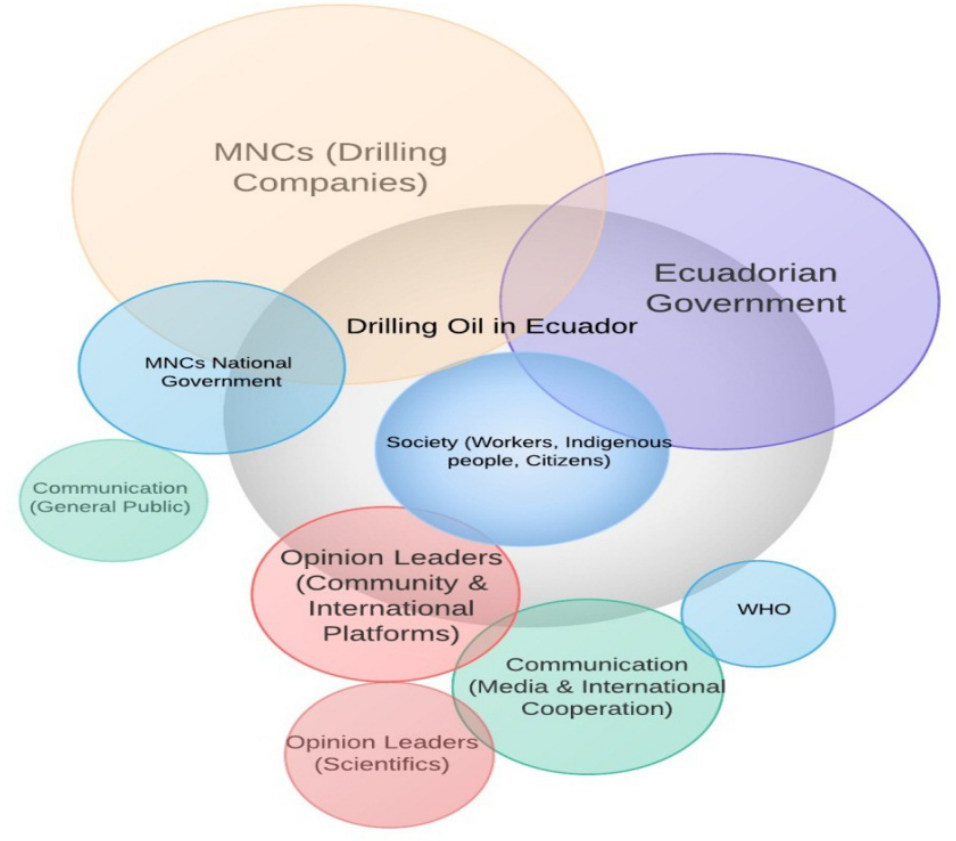

Figure 1: Venn diagram of a stakeholder analysis of oil drilling in Ecuador.

To improve the situation some Non-Governmental Organisations (NGOs) are publishing reports for different countries. The Yana Curi Report, for example, is one of the most important surveys and was published by Medicus Mundi, a Spanish NGO (Manuel Amunárriz Institute of Epidemiology and Community 
Health [13]). In August 2010, the WWF managed to get the Ecuadorian government to agree to leave some oil reserves untouched in exchange for billions of dollars in a new initiative called the Yasuni-ITT initiative (Halbert and Ingulli [25]). Health authorities, such as the WHO, are also trying to improve Ecuador's situation, but their influence is not enough to change the situation. Media plays a similar role in communicating the problem across the world. Its influence could be greater, but due to a lack of economic benefit, it does not attract much interest in mainstream media. The lack of media information results in a big deficiency of knowledge by the general public, which is another stakeholder with low influence and interest but a source of the large demand for oil. The indigenous leaders are a highly impacted stakeholder, but have low influence. An example is the case of MNC ARCO, where the oil drilling company made an agreement with indigenous leaders, creating a committee where three indigenous organizations participated in some of the decisions made. These indigenous organizations usually consisted of the leaders of the different tribes that were living in the drilling area, but in the end their power was very limited. The workers directly or indirectly connected with the drilling companies are an important stakeholder. A distinction between international and local workers should be made however, since the international workers are usually highly skilled workers that get high salaries whereas the locals are usually employed by foreign companies in temporary positions with lower salaries (Sawyer [26]).

It is important to note that the stakeholder analysis has a number of limitations. Although the Venn diagram illustrates how the stakeholders influence each other, the impacts of these interactions are not accounted for and only the most relevant stakeholders are considered for simplicity. Another limitation is the lack of a stakeholder representing the impacts on the environment. NGOs like Amazon Watch represent the environmental aspect to a certain degree, but further representation is needed. To compensate for these limitations, a Drivers Pressures State Impact Responses framework analysis was conducted, which clarifies the relationships between stakeholders and the causal links between actions and impacts of the different stakeholder groups (Kristensen [27]).

\section{Strategies and recommendations}

This report analyzes the oil exploration by MNCs in Ecuador from different perspectives. As such, it also analyzes several possible strategies. Both DPSIR and Stakeholder Analysis provide a clearer insight on the important participants in this issue and their impact and potential regulatory measures that could be implemented. Past cases of misconduct in oil exploration by MNCs should serve as an example to the future on how to properly act on the problem, preferably before it has even occurred. We have identified seven possible strategies and finally we will provide a recommendation on the best strategy to follow. 


\subsection{Temporary ban}

In November 2012, energy MNC giant BP was temporarily banned by the US government from entering into new contracts, due to the catastrophe in the Gulf of Mexico in 2010, when one of BPs wells blew out, causing an environmental disaster. The US Environmental Protection Agency (EPA) based its ban on a "lack of business integrity as demonstrated by the company's conduct with regard to the Deepwater Horizon blowout, explosion, oil spill and response” (Zubery [32]). The US EPA stated that this restriction will continue until BP can provide enough information to US EPA showing that it meets federal business standards. Banning oil drilling in Ecuador by the MNCs engaging in misconduct would be a great environmental solution for the citizens of Ecuador, but could cause problems as the national economy is mainly based on oil extraction. Hence, if the oil extractions are banned, other economic revenues should be found in the expansion of the Yasuní-ITT initiative to support the Ecuadorian economy in a sustainable way.

\subsection{Expansion of the Yasuní ITT Initiative}

Another strategy that could be pursued to improve the situation in Ecuador would be to receive all funds for the Yasuní-ITT or even increase the main objectives of this initiative to cover all of Ecuador. This strategy would be effective in preserving the environment and to improve the life conditions of Ecuadorian citizens; however this strategy also has some difficulties. If US\$3.6M are needed to solve the problem in the Yasuní National Park, how much would be needed to improve the conditions in all oil extractions in the rest of Ecuador? The oil revenues between January and November in 2010 were around US\$8.01M in Ecuador (Newswires [33]). So the amount needed to substitute these earnings would be huge. It was not easy to gather the funds to Yasuní-ITT, so it would be very difficult to source even more for rest of Ecuador. Still, an expansion of this initiative is recommended.

\subsection{Implementation of the precautionary principle}

Several corporate-sponsored articles on Chevron's website [34] claim insufficient proof that oil pollution has caused health problems in Ecuador. Most of the studies relating to health problems in the area already state the limitations and as San Sebastian and Hurtig [10] wrote: "Epidemiology, as an observational science, has inherent limitations". Since all observational scientific work is incomplete, society must not ignore knowledge it already has from this work, nor postpone actions that are demanded at a given time (Hill [35]). In lack of a complete risk assessment and an effective risk prevention technique, the precautionary principle states that "if an action or policy has a suspected risk of causing harm to the public or to the environment, in the absence of scientific consensus that the action or policy is harmful, the burden of proof that it is not harmful falls on those taking the action” (Ricci [36]). With contradictory scientific information from both sides of the legal case (Joseph [37]), there is an 
absence of scientific consensus, and therefore it is essential that the precautionary principle is applied to this issue. This would mean that instead of a company claiming that there is no proof that oil pollution and health problems are related, it would instead be required that the company prove that the effects of oil pollution are not harmful to human health before any project could be considered.

\subsection{Public participation}

It can be seen from the stakeholder analysis that the stakeholders with the most interest in the issue often have the least influence, e.g. local indigenous people. Social values must be respected if a development is to be sustainable (Wilkins [38]). Public participation in development planning is a way to promote social values and transparency in the planning process. It is therefore recommended that there is public participation in every step of the development including community meetings, proposals and environmental risk assessment. This public participation should involve obtaining informed consent from government officials, independent scientific and health authorities, indigenous people and local citizens after independent environmental education. This must be accompanied by a willingness of MNCs to acknowledge and utilise this participation in development decisions. By increasing the influence of these highly impacted stakeholders, MNCs will increase the control of the risk of pollution, for example by changing the location of an operation to an area at a further distance away from drinking water sources. If Chevron and other MNCs are serious about sustainability, there must be public participation in the decision-making process. This is a valuable strategy to risk prevention and risk abatement that was missing in the initial processes.

\subsection{Compensation and remediation}

As independent research has described the situation as a public health emergency, it is recommended that health treatment be implemented as soon as possible in the area. This can be funded by state profits from oil, and payout from the lawsuit against Chevron, should it be eventually paid. This should finance water and soil remediation, compensation for the citizens affected, health treatment, and other necessities that may need rehabilitation from the impact of oil exploration.

\subsection{Polluter pays principle}

Just as a Precautionary Principle should be implemented, the Polluter Pays Principle should be enforced vigorously. The Polluter Pays Principle states that "whoever is responsible for damaging the environment should bear the costs associated with it" (Cordato [39]) meaning that those who injure other people, either by direct harm or by degrading their property should be penalized. The payment is usually to the government in form of a tax, so it is not ensured that compensation is to the affected public. This is an efficient principle for the 
implementation of national environmental policies; it is also a principle that encourages the international harmonization of these policies. In combination with other measures, the Polluter Pays Principle is part of an effective risk prevention strategy, which when successfully implemented forces polluters to carefully monitor their environmental performance.

\subsection{Recommendations}

Based on our analysis of the environmental, health, social and ethical aspect of oil extraction in the Ecuadorian Amazon as well as the results of our Stakeholder Analysis and our DPSIR-analysis, we recommend that the Ecuadorian government adopt a combination of the various strategies. First, it is recommended that the Ecuadorian government place a temporary ban on new contracts with Chevron-Texaco, and other MNCs that have engaged in misconduct relating to pollution such as BP. This would assist in reducing damage to the environment, and MNCs would have to improve their environmental standards. The ban could be lifted when new policies are developed and the MNCs can meet these standards. There should be immediate compensation for the citizens affected to be used for health services, water and soil remediation. This compensation and remediation could also include the payout from the Chevron lawsuit if it is eventually paid. Ecuador's economy is largely reliant on exports of petroleum, however, there is potential for economic gain and environmental protection if the Yasuní-ITT initiative should be expanded to cover a wider area. In addition to this, the Ecuadorian government could add two key environmental principles to its environmental policy and a commitment to engage with the public. Adoption of the precautionary principle and the polluter pays principle will help ensure that any future developments are low risk and socially and environmentally sustainable. Thereby it can provide a solid platform for environmental management and monitoring that will protect the environment and people of Ecuador in the future.

\section{References}

[1] San Sebastian, M. et al. Outcomes of Pregnancy among Women Living in the Proximity of Oil Fields in the Amazon Basin of Ecuador, International Journal of Occupational and Environmental Health, 8(4), pp. 312-319. 2002.

[2] Mecham, J., Causes and Consequences of Deforestation in Ecuador, 2001, online. http://www.rainforestinfo.org.au/projects/jefferson.htm

[3] Finer, Matt. et al. Oil and Gas Projects in the Western Amazon: Threats to Wilderness, Biodiversity, and Indigenous People, 2009, online. http://www.plosone.org/article/info\%3Adoi\%2F10.1371\%2Fjournal.pone.0 002932

[4] San Sebastian, M., Hurtig. A., Oil exploitation in the Amazon basin of Ecuador: a public health emergency. Rev Panam Salud Publica, 15(3) (Washington), pp. 205-211, 2004 
[5] United Nations, Human Development Indicators: Forest Area, 2010, online. http://unstats.un.org/unsd/environment/forestarea.htm

[6] Shukla, J. et al. Amazon Deforestation and Climate Change, 2008, online.http://grads.iges.org/people/Shukla’s\%20Articles/1990/Amazonia\%2 0deforestation.pdf

[7] Viña, A. et al. Satellite Change Detection Analysis of Deforestation Rates and Patterns along the Colombia - Ecuador Border, Ambio: A Journal of the Human Environment, 33(3), pp. 118-125, 2004.

[8] Business Pundit, The World's Worst Environmental Disasters Caused by Companies, 2010, online. http:/www.businesspundit.com/the-worldsworst-environmental-disasters-caused-by-companies/

[9] San Sebastian, M and Hurtig, A., Geographical Differences in cancer incidence in the Amazon basin of Ecuador in relation to residence near oil fields. International Journal of Epidemiology,31(5),1021-1027, 2002

[10] San Sebastian, M., and Hurtig, A., Incidence of Childhood Leukemia and Oil Exploitation in the Amazon Basin of Ecuador, 2004, online. http://texacotoxico.org/eng/sites/default/files/ChildhoodLeukemia.pdf

[11] National Geographic, Central Amazon, n. d., online. http://travel.national geographic.com

[12] Maldonado, A., Narvaez. A., Ecuador ni es, ni será ya, país amazónico. Inventario de impactos petroleros -1. ed. Acción Ecológica: Quito, Ecuador, pp. 21-44, 2003

[13] Manuel Amunárriz Institute of Epidemiology and Community Health. Impacto de la actividad petrolera en poblaciones rurales de la amazonia ecuatoriana, 2000, online. http://www.inredh.org/archivos/documentos _ambiental/yanacuri_impacto_petroleo_amazonia_ecuador.pdf

[14] San Sebastian, M., and Hurtig, A., Epidemiology vs. epidemiology: the case of oil exploitation in the Amazon basin of Ecuador, 2005, online. http://ije.oxfordjournals.org/content/31/5/1021.full

[15] The Center for Economic and Social Rights (CESR), Rights Violations in the Ecuadorian Amazon: The Human Consequences of Oil Development, 1994, online. http://cesr.org/downloads/Rights\%20Violation\%20in\%20the \%20Ecuadorian\%20Amazon\%20The\%20Human\%20Consequences\%20of \%20Oil\%20Development\%201.pdf

[16] Tolan, S., Ecuador: Lost Promises, 2003, online. http://www.npr.org /programs/morning/features/2003/jul/latinoil/

[17] Valdivia, G., 2007. The “Amazonian Trial of the Century": Indigenous Identities, Transnational Networks, and Petroleum in Ecuador, Alternatives: Global, Local, Political, 32(1), pp. 45-47, 2007

[18] Haller, T., Blöchlinger, A., John, M., Marthaler, E. and Ziegler, S., Fossil Fuels, Oil Companies, and Indigenous People: Strategies of multinational oil companies, states, and ethnic minorities; Impact on environment, livelihoods, and cultural change. ed. LIT, Münster, pp. 283-362, 2007

[19] Kimerling, J., Indigenous Peoples and the Oil Frontier in Amazonia: The Case of Ecuador, Chevron-Texaco and Aguinda, n.d., online. http://www.ruthgroup.org/wp-content/documents/Chevron_kimerling.pdf 
[20] Amazon Defense Coalition, Summary of Evidence against Chevron in Ecuador Trial, 2012, online. http://chevrontoxico.com/assets/docs/2012-01evidence-summary.pdf

[21] Cueto, S., Oil's not well in Latin America: Curing the short comings of the current international environmental law regime in dealing with industrial oil pollution in Latin America through codes of conduct, 1998, online. http://www.jdsupra.com/legalnews/oils-not-well-in-latin-america-curing20483/

[22] World Health Organization (WHO), What is Stakeholder Analysis, n.d., online. http://www.who.int/management/partnerships/overall/WhatisStake holderAnalysis.pdf

[23] Schmeer, K., Stakeholder Analysis Guidelines, 2001, online. http://www.who.int/workforcealliance/knowledge/toolkit/33.pdf

[24] Index Mundi, Ecuador Economy Profile, 2012, online. http://www.indexmundi.com/ecuador/economy_profile.html

[25] Halbert, T., Ingulli, E., Law \& Ethics in the Business Environment, ed. South-Western, Mason, pp. 42-45, 2012

[26] Sawyer, S., Property in Question: Value Transformation in the Global Economy, Crude properties: The sublime and slime of oil Operations in the Ecuadorian Amazon., ed. Berg, New York, pp. 85-109, 2004

[27] Kristensen, P., The DPSIR Framework; National Environmental Research Institute, Denmark. 2004, online. http://enviro.lclark.edu:8002/rid= 1145949501662_742777852_522/DPSIR\%200verview.pdf

[28] Finer, M. et al. Leaving the Oil under the Amazon: Ecuador's Yasuní-ITT Initiative, 2009, online. http://onlinelibrary.wiley.com/doi/10.1111/j.17447429.2009.00587.x/pdf

[29] Yasuní-ITT, Crea un nuevo mundo, 2012, online. http://Yasuníitt.gob.ec/quees.aspx

[30] Naughton-Treves, L, et al. Expanding Protected Areas Incorporating Human Resource Use: a Study of 15 Forest Parks in Ecuador and Peru, 2006, online. http://sspp.proquest.com/archives/vol2iss2/0602-009. naughton-treves.html

[31] Svarstad, H. et al. Discursive biases of the environmental research framework DPSIR, 2007, online. http://www.sciencedirect.com/science /article/pii/S0264837707000464

[32] Zubery, M. A., Business Recorder. BP banned from US government contracts, 2012, online. http://www.brecorder.com/top-news/108-pakistantop-news/92706-bp-banned-from-us-government-contracts.html

[33] Newswires, D. J., America Economia, 2012, online. http://www.america economia.com/economia-mercados/finanzas/ecuador-ingresos-porexportaciones-de-petroleo-suman-us8010m-noviembre-de

[34] Chevron, Ecuador Environmental Claims, 2012, online. http://www.chevron.com/ecuador/

[35] Hill, A., Environment and Disease. Association or Causation?, Proceedings of the Royal Society of Medicine, 58(5), pp. 300, 1965 
[36] Ricci, P., Precaution, uncertainty and causation in environmental decisions, 2003, online. http://www.sciencedirect.com/science/article/pii/S016041200 2001915

[37] Joseph, S., Protracted lawfare: the tale of Chevron Texaco in the Amazon, 2012, online. http://e-elgar.metapress.com/content/r7861048p1773476/

[38] Wilkins, H., The Need for Subjectivity in EIA: discourse as a tool for sustainable development, 2003, online. http://www.sciencedirect.com /science/article/pii/S0195925503000441

[39] Cordato, R., The Polluter Pays Principle - A Proper Guide for Environmental Policy, 2006, online. http://iret.org/pub/SCRE-6.PDF 